\title{
Biochemical composition of cultured algae Catenella nipae at Salimpur coast Chittagong
}

\begin{abstract}
Macro-benthic algae Catenella nipae was cultured from November '06 to August ' 07 at the Salimpur planted mangrove area. Some biochemical compositions of the cultured C. nipae of the study area were recorded during the investigation period. The mean value of biochemical composition such as moisture, ash, fat, protein, crude fibre and carbohydrate were estimated as $17.12 \pm 0.34 \%, \quad 5.38 \pm 0.23 \%, \quad 1.32 \pm 0.07 \%, \quad 11.50 \pm 0.05 \%$, $2.36 \pm 0.04 \%$ and $62.31 \pm 0.32 \%$, respectively on dry weight basis of C. nipae. The proximate composition of $C$. nipae showed good amount of nutritive value, therefore, this seaweed may be culture commercially and can be used for human food and food additives in the local market of Bangladesh.
\end{abstract}

Keywords: carbohydrate, crude fibre, mangrove area, biochemical compositions, seaweeds
Volume 3 Issue 5 - 2018

\author{
Mohammad Rokan Uddin, Rashedul Alam \\ Chowdhury SM
}

Institute of Marine Sciences and Fisheries, University of Chittagong, Bangladesh

\begin{abstract}
Correspondence: Mohammad Rokan Uddin, Institute of Marine Sciences and Fisheries, University of Chittagong, Chittagong-433।, Bangladesh, Tel +880 I819 0979 19, Email rokancu@gmail.com
\end{abstract}

Received: August 02, 2018 | Published: September 21, 2018

\section{Introduction}

Seaweeds are sedentary organisms, growing on the rocky or hard substratum of intertidal water of World Ocean. ${ }^{1}$ They belong to the group of plants known as algae containing some of the most primitive members of the plant kingdom. ${ }^{2}$ Okazaki $^{3}$ stated, "Seaweeds as the name implies covers the macroscopic plant life of the sea except the flowering plants". It has immense importance both for human and faunal communities. Prehistorically, people have been consuming seaweed either raw or cooked condition. Novaczek ${ }^{4}$ reported that seaweeds have large amount of protein, amino acids, lipids, vitamins and minerals, polysaccharides and dietary fibers. Some compounds of seaweeds control high blood pressure, level of cholesterol, and prevent strokes. These can also be used as remedy for rheumatism, diarrhea, and for controlling the growth of tumors. The culture of seaweed for human consumption is a relatively new enterprise. The concept about seaweed and its cultivation is limited to the scientific community, people hardly known about its importance and culture technique in developing countries. The status of seaweed cultivation in Bangladesh is still at the nascent stage. The study is first experiment of Catenella nipae culture on bamboo poles in the intertidal waters of Salimpur coast in Bangladesh where plenty of C. nipae grows naturally remains unutilized for long time. In addition, now-a-days utilization of algae as human food has been increasing in many countries like China, Japan, Philippines and Myanmar. ${ }^{5}$ Whereas the mass people of Bangladesh do not know that the algae can be used as human food. To grow interest on algae, knowledge on proximate composition and its nutritive value is essential. Hence, present investigation analyzed the proximate composition of algae Catenella nipae.

\section{Materials and methods}

The investigation was carried out on November 2006 to August 2007 at Salimpur mangrove area. Bamboo poles were used for culture of Catenella nipae. A total area of $5 \mathrm{~m}$ x $5 \mathrm{~m}$ was selected. To culture C. nipae on bamboo poles, at first bamboo poles were collected and cut into $0.5 \mathrm{~m}$ size length each. Within the culture area bamboo poles were installed maintaining $0.5 \mathrm{~m}$ distance between two consecutive poles. Then body segments of $C$. nipae from the nature were collected and were attached in the bamboo poles with the help of thread. Routine checked of the culture system was done. After three months culture experimental algal species was collected carefully with the help of a sharp knife and taken in to plastic bag. All the collected samples are stored in refrigerator for further analysis.

\section{Sample preparation}

The frozen algae were kept on tray until they attained air temperature. Then wash thoroughly with fresh tap water to remove undesirable dirt and others. After that they were dept in a slanting position to remove water. Sample were cut in to small pieces and then prepared ready for experiment. The samples were macerated using mortar paste and were separately used for investigation.

\section{Analysis}

Moisture contents in wet samples were estimated by the following Oven method. ${ }^{6}$ Ash content is determined in feedstuffs by calcinations. ${ }^{7}$ By following the Soxhlet extraction method of Osborne et al., ${ }^{7}$ fat can be conveniently determined by extracting the material paste with light petroleum (petroleum sprit B.P $40^{\circ} \mathrm{C}-60^{\circ} \mathrm{C}$ ). Protein content was determined by the micro Kjeledahl method proposed by Pearso ${ }^{8}$ Crude fibre content was determined by the calcinations method. ${ }^{7}$ Following Clegg-anthrone method $^{9}$ the total amount of carbohydrate is determined.

\section{Results}

Average moisture content was determined as $17.12 \pm 0.34 \%$. Highest value was found $17.60 \%$ during July 2007 and lowest value 16.87\% was recorded during April 2007 (Table 1 \& Figure 1). Mean ash content was determined as $5.38 \pm 0.23 \%$. Highest value was found $5.71 \%$ during January 2007 (Figure 1) and lowest value 5.20\% was recorded during April 2007 (Table 1 \& Figure 2). Mean ash content was determined as $1.32 \pm 0.07 \%$. Highest value was found $1.39 \%$ during April 2007 and lowest value 1.22\% was recorded during July 2007 (Table 1 \& Figure 3). Protein content was determined as $11.50 \pm 0.05 \%$. Highest value was found $11.57 \%$ during January 2007 and lowest value $11.46 \%$ was recorded during July 2007 (Table $1 \&$ Figure 3). Average crude fibre content was determined as $2.36 \pm 0.04 \%$. Highest value was found $2.40 \%$ during July 2007 and lowest value $2.31 \%$ was recorded during April, 2007 (Table $1 \&$ Figure 2). Average carbohydrate content was determined as $62.31 \pm 0.32 \%$. Highest value was found $62.76 \%$ during April 2007 and lowest value $62.07 \%$ was recorded during July 2007 (Table 1 \& Figure 3). 
Table I Proximate composition of Catenella nipae (January- July, 2007) on the basis of dry weight

\begin{tabular}{lllllll}
\hline Month & \% of Moisture & \% of Ash & \% of Fat & \% of Protein & \% of Crude fibre & \% of Carbohydrate \\
\hline January & 16.9 & 5.71 & 1.35 & 11.57 & 2.38 & 62.09 \\
April & 16.87 & 5.2 & 1.39 & 11.47 & 2.31 & 62.76 \\
July & 17.6 & 5.25 & 1.22 & 11.46 & 2.4 & 62.07 \\
Mean & 17.12 & 5.38 & 1.32 & 11.5 & 2.36 & 62.31 \\
SD & \pm 0.34 & \pm 0.23 & \pm 0.07 & \pm 0.05 & \pm 0.04 & \pm 0.32 \\
\hline
\end{tabular}

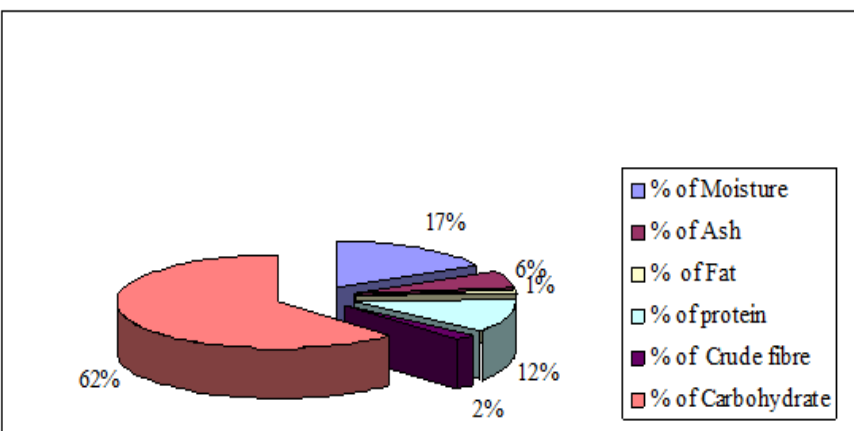

Bio-chemical composition of Catenella nipae in January

Figure I Bio-chemical composition of C. nipae in January.

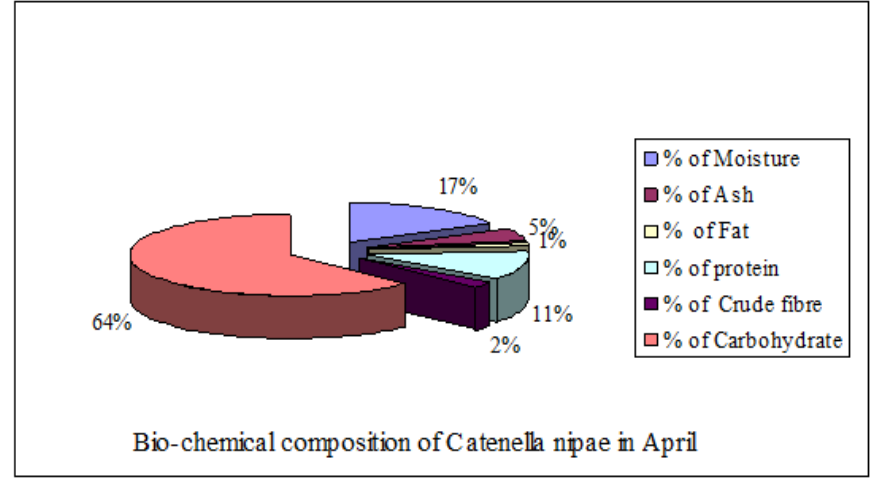

Figure 2 Bio-chemical composition of C. nipae in April.

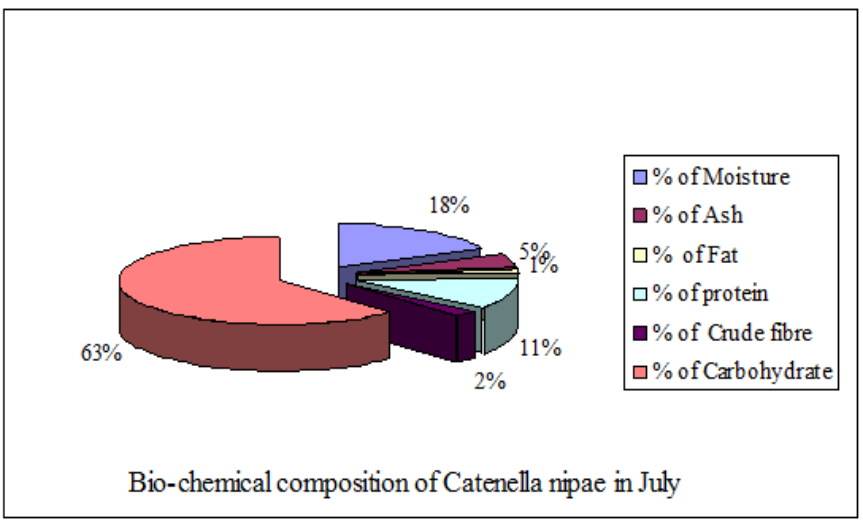

Figure 3 Bio-chemical composition of C. nipae in July.

\section{Discussion}

Chapman (1970) recommended proximate composition of seaweed varies with space and also depend upon the season of the year and the relative proportion of the different of the samples. The main proximate composition of seaweeds are moisture, ash (minerals), protein, fat, crude fibre and nitrogen free-extract. Hossain ${ }^{10}$ recorded the moisture, ash, protein, fat, crude fiber and carbohydrate ranged from $(17.16-18.22 \%),(16.30-17.85 \%),(14.64-15.53 \%),(1.86-$ $2.28 \%),(2.96-3.23 \%)$ and $(43.76-45.98 \%)$ on dry wt. basis in $C$. nipae at Fauzdarhat mangrove area. Talukder ${ }^{11}$ recorded the moisture, ash, protein, lipid ranged from $(1.02-1.70 \%),(3.63-6.99 \%),(11.10$ $15.33 \%),(1.07-2.80 \%)$, on wet wt. basis in C. nipae at Fauzdarhat mangrove area. Zafar ${ }^{12}$ recorded the protein, lipid, moisture, ash as $9.92 \%, 1.95 \%, 84.56 \%, 4.85 \%$, on wet wt. basis of Catenella nipae at Fauzdarhat mangrove area. Novaczek ${ }^{4} \& Z_{\text {Zafar }}{ }^{12}$ recommended that Caulerpa racemosa, Hypnea spp., Enteromorpha spp. and Catenella nipae are used for human dietary items for reducing high blood pressure, rheumatism, cholesterol level, growth of tumors and diarrhea. In the present work the proximate composition of Catenella nipae, shows the good nutrition value. The mean value of biochemical composition i.e.; moisture, ash, fat, protein, crude fibre and carbohydrate were estimated as $17.12 \pm 0.34 \%, 5.38 \pm 0.23 \%, 1.32 \pm 0.07 \%$, $11.50 \pm 0.05 \%, 2.36 \pm 0.04 \%$ and $62.31 \pm 0.32 \%$ respectively on dry weight basis of $C$. nipae. So it may be used as human food and also use as a fish feed.

\section{Conclusion}

This study shows that $C$. nipae at Salimpur mangrove area possesses significant amount of nutritive value which can fulfill the nutritional requirement of the people of Bangladesh. No systematic study on this economic seaweed has done in Bangladesh before. Therefore, the present study can be the path-finder on the detailed study of specific seaweed for the enrichment of the study of phycology in Bangladesh.

\section{Acknowledgements}

None.

\section{Conflict of interest}

The author declares there is no conflict of interest.

\section{References}

1. Santhanam RN Remanathan, Jagathusan, G. Coastal aquaculture in India. C. B. S. Publishers and Distributors. 1990;159-162.

2. Chapman VJ. Seaweed and their Uses. London: Chapman and Hall. Gracilaria edulis from Cape Negrais to Maung Shwe Lay Gyaing. Burma Research Congress. 1970;6. 
3. Okazaki A. Seaweeds and their uses in Japan. Tokyo University press, Japan. 1971;170.

4. Novaczek I. A guide to the common edible and medicinal sea plants of the Pacific Island. University of South Pacific. 2001;1- 48.

5. Torno GCJR. Philippines Seaweeds, National Book Store Inc., 1988;321.

6. Lovell RT. Laboratory manual for fish feed analysis and fish nutrition studies, Auburn Universities. 1975;3- 5.

7. Osborne DR, Voogt P. The analysis of nutrients in food. Academic Press, London, UK, 1978;240.

8. Pearson D. The chemical analysis of feeds. 7 th ed. Churchill Livingstone (London). 1976;488-516.
9. Clegg KM. Journal of Science. Food Agriculture. 1956;7:40.

10. Hossain Z. Proximate composition of Catenella nipae in the two different mangrove vegetations with reference to some hydrological parameters. B.Sc. Term paper, IMS. University of Chittagong. 2005;25.

11. Talukder MAU. Study on macro- benthic blgae in the intertidal mangrove area of Fauzdarhat Coast, Chittagong. M.Sc. Thesis, IMS. University of Chittagong. 2004;101.

12. Zafar M. Feasibility study of seaweed culture as a livelihood options for the poor coastal communitie. Final Report, SUFER, DFID, IMS, CU. Bangladesh. 2004;18. 